\title{
Hybrid epitaxy technique for the growth of high-quality AllnAs and GalnAs layers on InP substrates
}

Thierno Mamoudou Diallo, Alex Brice Poungoué Mbeunmi, Mohamed El-Gahouchi, Mourad Jellite, Roxana Arvinte, Mohammad Reza Aziziyan, Richard Arès, Simon Fafard, and Abderraouf Boucherif

Citation: Journal of Vacuum Science \& Technology B 37, 031208 (2019); doi: 10.1116/1.5088962

View online: https://doi.org/10.1116/1.5088962

View Table of Contents: https://avs.scitation.org/toc/jvb/37/3

Published by the American Vacuum Society

\section{ARTICLES YOU MAY BE INTERESTED IN}

Mesoporous germanium morphology transformation for lift-off process and substrate re-use Applied Physics Letters 102, 011915 (2013); https://doi.org/10.1063/1.4775357

Chemical beam epitaxy growth of AIGaAs/GaAs tunnel junctions using trimethyl aluminium for multijunction solar cells

AIP Conference Proceedings 1556, 48 (2013); https://doi.org/10.1063/1.4822197

Liquid-phase exfoliation of fluorinated graphite to produce high-quality graphene sheets

Journal of Vacuum Science \& Technology B 37, 031801 (2019); https://doi.org/10.1116/1.5081961

\section{AVS Quantum Science}




\title{
Hybrid epitaxy technique for the growth of high-quality AllnAs and GalnAs layers on InP substrates
}

\author{
Thierno Mamoudou Diallo, ${ }^{1,2, a)}$ Alex Brice Poungoué Mbeunmi, ${ }^{1,2, a)}$ Mohamed El-Gahouchi, ${ }^{1,2}$ \\ Mourad Jellite, ${ }^{1,3}$ Roxana Arvinte, ${ }^{1,3}$ Mohammad Reza Aziziyan, ${ }^{1,2}$ Richard Arès, ${ }^{1,3}$ \\ Simon Fafard, ${ }^{1,2}$ and Abderraouf Boucherif ${ }^{1,3, b)}$ \\ ${ }^{1}$ Interdisciplinary Institute for Technological Innovation (3IT), CNRS UMI-3463, Université de Sherbrooke, \\ 3000 boul. de l'Université, Sherbrooke, Québec J1K 0A5, Canada \\ ${ }^{2}$ Department of Electrical and Computer Engineering, Faculty of Engineering, Université de Sherbrooke, \\ 2500 boul. de l'Université, Sherbrooke, Québec J1K 2R1, Canada \\ ${ }^{3}$ Department of Mechanical Engineering, Faculty of Engineering, Université de Sherbrooke, 2500 boul. \\ de l'Université, Sherbrooke, Québec J1K 2R1, Canada
}

(Received 15 January 2019; accepted 1 April 2019; published 18 April 2019)

\begin{abstract}
The quality and properties of epitaxial films are strongly determined by the reactor type and the precursor source phase. Such parameters can impose limitations in terms of background doping, interface sharpness, clustering, phase separation, and homogeneity. The authors have implemented a hybrid epitaxy technique that employs, simultaneously, vapor and solid sources as group III precursors. The system combines the high throughput and the versatility of gas sources as well as the high purity of solid sources. Using this technique, the authors successfully demonstrated epitaxial growth of $\mathrm{Al}_{0.48} \mathrm{In}_{0.52} \mathrm{As}$ and $\mathrm{Ga}_{0.47} \mathrm{In}_{0.53}$ As layers on Fe-doped semi-insulating $\mathrm{InP}(001)$ substrates with interesting properties, compared with the epilayers grown by more standard techniques (chemical beam epitaxy, metal-organic chemical vapor deposition, and MBE). For AlInAs growth, trimethylindium and solid aluminum were used as In and $\mathrm{Al}$ precursors, respectively. In the case of GaInAs, triethylgallium and solid indium were used, respectively, as Ga and In precursors. Thermally cracked arsine $\left(\mathrm{AsH}_{3}\right)$ was used as an As (group V) precursor for both alloys. The AlInAs and GaInAs epilayers grown at a temperature of $500{ }^{\circ} \mathrm{C}$ exhibited featureless surfaces with RMS roughness of 0.2 and $1 \mathrm{~nm}$, respectively. Lattice mismatch is of $134 \mathrm{ppm}$, for AlInAs, and $-96 \mathrm{ppm}$, for GaInAs, which were determined from high-resolution x-ray diffraction (HR-XRD) patterns and showed a large number of Pendellösung fringes, indicating a high crystalline quality. An FWHM of 18.5 arcs was obtained for GaInAs epilayers, while HR-XRD mapping of a full 2-in. wafer confirmed a viable lattice mismatch homogeneity (standard deviation of $0.026 \%$ ) for as-grown layers. The authors observed room-temperature background doping values as low as $3 \times 10^{15} \mathrm{~cm}^{-3}$, for AlInAs, and $1 \times 10^{15} \mathrm{~cm}^{-3}$, for GaInAs. Analysis of the PL spectra at $20 \mathrm{~K}$ showed an FWHM of $8 \mathrm{meV}$, for AlInAs, and $9.7 \mathrm{meV}$, for GaInAs, demonstrating a very good optical quality of the epilayers. In addition, they have investigated the effects of the growth temperature and of the arsine pressure on epilayer properties. They also discuss the optimum conditions for the growth of high-quality $\mathrm{Al}_{0.48} \mathrm{In}_{0.52} \mathrm{As}$ and $\mathrm{Ga}_{0.47} \mathrm{In}_{0.53} \mathrm{As}$ layers on $\mathrm{InP}(001)$ substrates using this hybrid epitaxy technique. Published by the AVS. https://doi.org/10.1116/1.5088962
\end{abstract}

\section{INTRODUCTION}

The lattice-matched growth of $\mathrm{Al}_{0.48} \mathrm{In}_{0.52} \mathrm{As}$ and $\mathrm{Ga}_{0.47} \mathrm{In}_{0.53}$ As (hereafter AlInAs and GaInAs) compound semiconductors on InP substrates is feasible, which makes them quite compatible. These ternary alloys are of great interest for fabrication of electronic and optoelectronic devices $^{1}$ such as HEMTs, avalanche photodiodes (APDs), and lasers. For example, AlInAs has been investigated for replacing InP as the multiplication layer in APD, since, compared to InP, it has larger bandgap, higher ionization ratio, better thermal stability, and lower excess noise characteristics. $^{2,3}$ On the other hand, GaInAs is attractive due to its high electron mobility, peak velocity, ${ }^{4-6}$ high absorption

Note: This paper is part of the Special Topic Collection from 34th North American Molecular Beam Epitaxy Conference 2018.

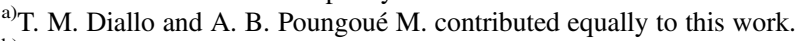

b) Author to whom correspondence should be addressed: Abderraouf. boucherif@usherbrooke.ca coefficient, and direct bandgap. Various techniques such as molecular-beam epitaxy (MBE), metal-organic chemical vapor deposition (MOCVD), and chemical beam epitaxy (CBE) have been employed for epitaxial growth of highquality AlInAs and GaInAs layers on InP substrates. However, the growth of epilayers with sharp interfaces is relatively difficult, compared to the commonly used $\mathrm{AlGaAs} / \mathrm{GaAs}$ heterostructure, which is known to have an ideal interface. ${ }^{7-10}$ In the case of AlInAs alloys, obtaining epitaxial layers with good structural, optical, and electrical quality is complicated, partially due to the difference in bond strength between In-As and Al-As, and partially due to carbon $(\mathrm{C})$ and oxygen $(\mathrm{O})$ contaminations. ${ }^{11}$ The difficulties for the growth of GaInAs epilayers are associated with the inhibition of triethylgallium (TEGa) decomposition by indium (In), the spinodal decomposition, and the sensitivity of alloy composition to growth temperature. ${ }^{4}$ Since some of these problems are directly related to the reactor type and the precursor source phase, several studies 
focused on the epitaxial growth of AlInAs and GaInAs on InP substrates using either vapor sources (e.g., MOCVD, CBE, and others) ${ }^{4,12,13}$ or solid sources (e.g., MBE). ${ }^{14,15}$ In this respect, effects of growth conditions on material properties and epilayer surface morphology have been extensively investigated. ${ }^{16-20}$ These studies revealed the challenges that must be overcome as well as the optimized parameters that must be undertaken, in order to attain conditions for growing high-quality AlInAs and GaInAs layers using solid or vapor sources. It is reported that growth temperature, V/III ratio, and the precursor's nature are the crucial parameters that determine the overall quality of epitaxial layers. For instance, applying an improper growth temperature could lead to the formation of clusters and high density of point defects that ultimately will degrade the structural, electrical, and optical properties of the grown epilayer. ${ }^{16}$

While using solid sources should alleviate high background doping and interface sharpness issues, clustering and phase separation are still challenging issues in this system. On the other hand, vapor sources offer a better homogeneity of grown layers, compared to solid sources, although a high background doping ${ }^{21,22}$ is found. The foregoing discussion underlies that growth of high-quality AlInAs and GaInAs epilayers still suffer from some unresolved issues when only solid or vapor sources are used, whereas using individual vapor or solid sources were widely explored, to our knowledge, no hybrid growth technique that combines the two solid and gas sources have been explored.

In this work, we have investigated epitaxial growth of AlInAs and GaInAs layers on InP substrates using a hybrid epitaxy technique that uses, at the same time, solid and gas sources as group III, and hydride as group V. The main objective was to combine the high throughput and versatility of gas sources with the high purity (required for critical layers) of solid sources in order to obtain high-quality films with sharp interfaces and low background doping. We discuss the effects of growth parameters on the surface morphology as well as the structural and the optical properties of AlInAs and GaInAs layers grown using this hybrid technique.

\section{EXPRIMENTAL DETAILS}

The epitaxial growth was carried out in a modified VG Semicon VG90H CBE reactor equipped with both solid and gas precursors sources. The growth chamber is equipped with a reflection high energy electron diffraction (RHEED) monitoring system that was used to record the in situ RHEED pattern evolution during the growth process. All the samples studied in this work were grown on epi-ready, Fe-doped, semi-insulating, and double-side polished (001) InP substrates (from AXT Inc., USA). For the growth of the epilayers by hybrid epitaxy technique, trimethylindium (TMIn) and TEGa were used as gas sources, while $\mathrm{Al}$ and In were employed as solid sources (i.e., group III precursors). In the case of AlInAs and GaInAs epilayers grown by CBE technique (data presented in supplementary material ${ }^{45}$ ), triethylaluminum (TEAl), TMIn, and TEGa were used as group III gas precursors. High purity (6N5) thermally cracked arsine $\left(\mathrm{AsH}_{3}\right)$ at $950{ }^{\circ} \mathrm{C}$ was used as an As precursor (i.e., group $\mathrm{V}$ precursor). TMIn and solid In sources were used, respectively, for hybrid growth of AlInAs and GaInAs epilayers. The In and $\mathrm{Al}$ effusion cells were calibrated in order to determine the growth rate. The used reactor is equipped with a cryopanel, which is cooled by liquid nitrogen, and the system is pumped by a $2500 \mathrm{l} / \mathrm{s}$ turbo. The background pressure of the reactor is $1 \times 10^{-7}$ Torr. However, during the growth, the pressure in the chamber was $1 \times 10^{-4}$ Torr. The growth temperature $\left(\mathrm{T}_{\mathrm{g}}\right)$ was monitored by thermocouple and absorption band edge spectroscopy thermometry. For the epitaxial growth of AlInAs epilayers, $1 \times 1 \mathrm{~cm}^{2}$ InP substrates were mounted on Molybdenum (Mo) blocks. However, for the GaInAs growth, the InP substrates were In-soldered on Mo blocks, to prevent any temperature shifts during the process, since it is known that this alloy is very sensitive to the temperature variations. ${ }^{4}$ Prior to growth, a thermal cleaning of the InP substrate, at $540{ }^{\circ} \mathrm{C}$ for $5 \mathrm{~min}$ under an $\mathrm{AsH}_{3}$ overpressure, was adopted to desorb the native oxide from the surface. In the case of AlInAs, we varied the $\mathrm{AsH}_{3}$ pressure in the range of 3-40 Torr to investigate the V/III ratio effect on the structural and morphological properties of epilayers. To calibrate the lattice mismatch of both alloys, we changed the gas pressure, while keeping all the other growth parameters constant.

The epilayers morphology was characterized by optical microscopy in Nomarski differential interference contrast (DIC) configuration and atomic force microscopy (AFM) using a Veeco Instruments Nanoscope IIIa. The structural properties such as lattice mismatch, XRD linewidth, epilayer composition, GaInAs epilayer uniformity, and thickness were investigated by a Philips Analytical High-resolution $\mathrm{x}$-ray diffraction (HR-XRD) system. The HR-XRD measurements were performed around the InP (100) symmetry. Samples were exposed to an incident beam of $\mathrm{Cu} \mathrm{K} \alpha_{1}$ radiation, and the (004) reflection detected from the samples was used to analyze the rocking curve Bragg peak separations. Based on the peak separations, we determined the structural properties of the epilayers. Low-temperature photoluminescence (LTPL) spectra were collected at $20 \mathrm{~K}$ by exciting the samples with a diode laser emitting at a wavelength of $532 \mathrm{~nm}$. The LTPL signal of AlInAs epilayers was detected using a Hamamatsu R9268 photomultiplier that was effective in the wavelength range $185-1010 \mathrm{~nm}$. Then, the LTPL signal of GaInAs epilayers was collected with an InAs EG\&G detector, effective in the wavelength range 1.5-3.5 $\mu \mathrm{m}$. Hall effect measurements in Van der Pauw configuration were performed to determine the epilayers background doping. Surface and interface depletion corrections of free carrier density were performed in order to obtain the accurate value of the carrier concentration. $^{23}$

\section{RESULTS AND DISCUSSION}

\section{A. Sources calibration}

Figure 1 shows the growth rate as a function of effusion cells temperature, for $\mathrm{Al}$ cell [Fig. 1(a)] and In cell [Fig. 1(b)]. To calibrate $\mathrm{Al}$ and In effusion cells, respectively, 

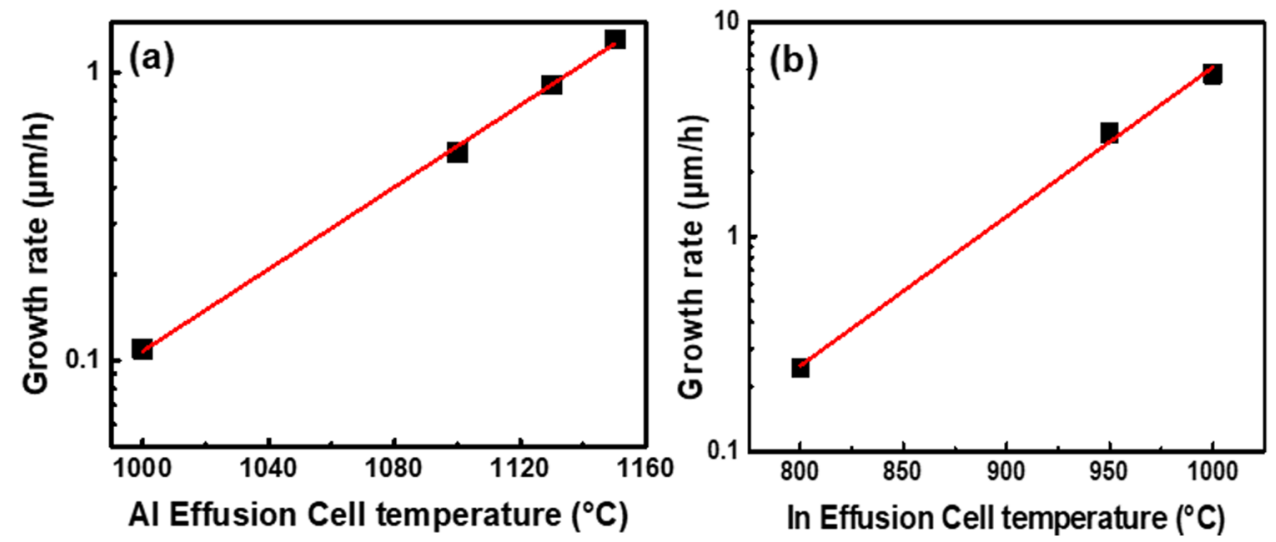

FIG. 1. Effusion cells calibration for (a) $\mathrm{Al}$ cell during AlAs/GaAs growth at $\mathrm{T}_{\mathrm{g}}=565^{\circ} \mathrm{C}$ and (b) In cell during $\operatorname{InP} / \operatorname{InP}$ growth at $\mathrm{T}_{\mathrm{g}}=530^{\circ} \mathrm{C}$.

AlAs layers were grown on GaAs (001) substrates at a growth temperature $\left(\mathrm{T}_{\mathrm{g}}\right)$ of $565^{\circ} \mathrm{C}$, and $\mathrm{InP}$ layers were grown on InP (001) substrates at $\mathrm{T}_{\mathrm{g}}=530^{\circ} \mathrm{C}$. Thus, the growth rates were determined as a function of effusion cell temperatures.

As it can be seen in Fig. 1, for either cell, the growth rate increased exponentially with the cell temperature. Such a nonlinear behavior, also known as thermo-ionic phenomenon, has been described by Hertz-Knudsen or Clapeyron law. ${ }^{24}$ During the epitaxial growth of AlInAs and GaInAs layers, the effusion cell temperatures were kept at $1050^{\circ} \mathrm{C}$, for $\mathrm{Al}$ cell, and $866^{\circ} \mathrm{C}$, for In cell. This led to a growth rate of $0.4 \mu \mathrm{m} / \mathrm{h}$ for AlInAs layers and $1.25 \mu \mathrm{m} / \mathrm{h}$ for GaInAs layers. Note that beam flux measurements were not available in order to assess periodically the equivalent beam pressure of the effusion cells in this study. Such beam flux measurements, RHEED oscillation measurements, and/or x-ray diffraction on the calibration of superlattices would help to quantify potential cell depletion effects, but for the present study, the effusion cell depletion effects remain a potential source of uncertainty. However, it is expected that our results [Figs. 2(a) and 8] are not significantly affected by the effect of effusion cells depletion on alloy composition.

\section{B. Growth of $\mathrm{Al}_{0.48} \mathrm{In}_{0.52}$ As layers}

\section{Growth conditions}

The effect of $\mathrm{T}_{\mathrm{g}}$ and $\mathrm{AsH}_{3}$ pressure on structural and morphological properties was investigated. In order to study the impact of $\mathrm{T}_{\mathrm{g}}$, the $\mathrm{AsH}_{3}$ pressure was fixed at 10 Torr, while
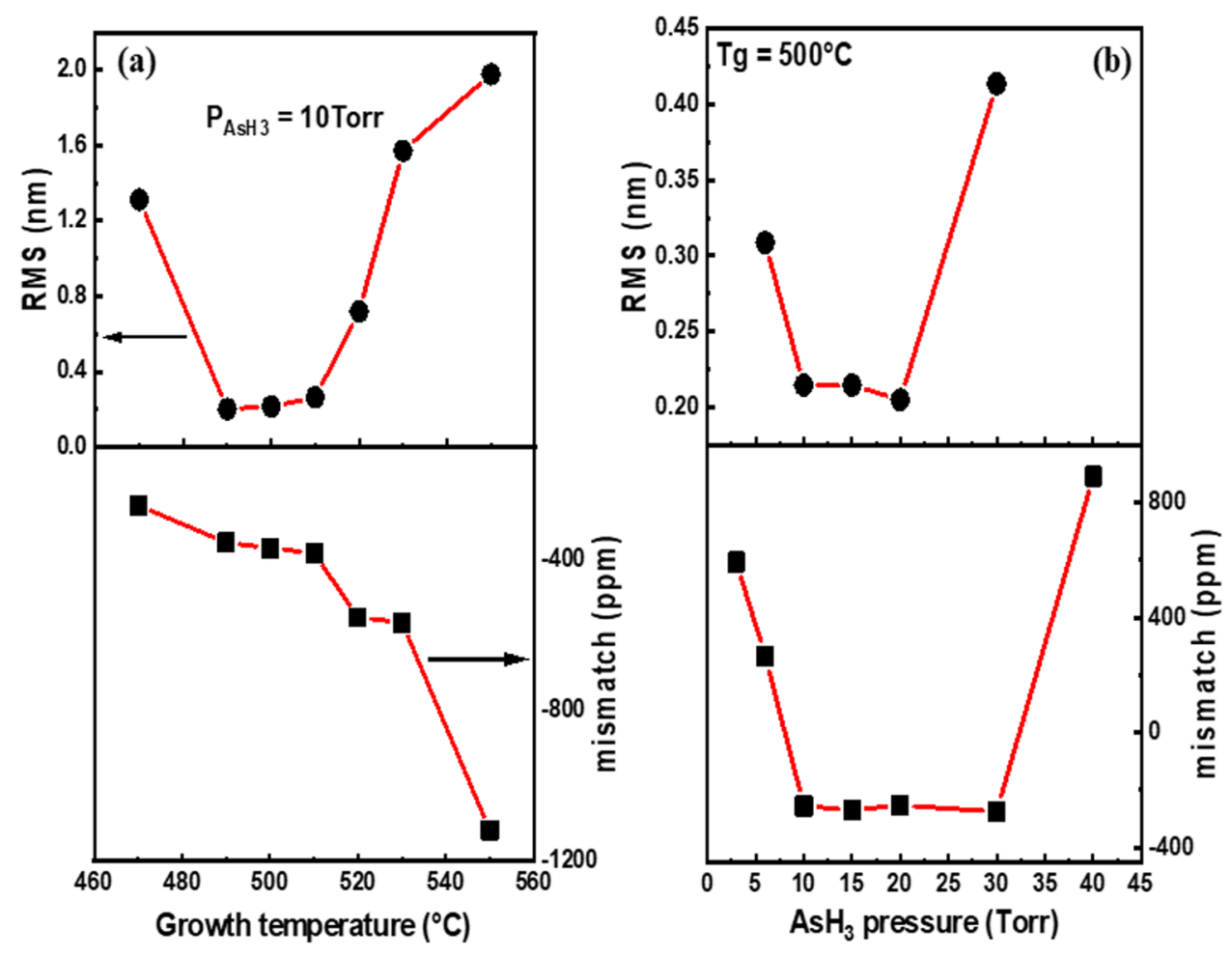

FIG. 2. Lattice mismatch and surface roughness (RMS) of AlInAs layers as a function of (a) $\mathrm{T}_{\mathrm{g}}$ and (b) AsH $\mathrm{H}_{3}$ pressure. 
the $\mathrm{T}_{\mathrm{g}}$ was varied in the range of $470-550^{\circ} \mathrm{C}$. The effect of $\mathrm{AsH}_{3}$ pressure was studied by varying the pressure in the range of 3-40 Torr while keeping the $\mathrm{T}_{\mathrm{g}}$ fixed at $500{ }^{\circ} \mathrm{C}$.

Figure 2(a) shows the lattice mismatch and the surface roughness (RMS) of AlInAs layers as a function of $T_{g}$, while $\mathrm{AsH}_{3}$ pressure was fixed. As it can be seen in Fig. 2(a), the tensile strain of $\mathrm{Al}_{0.48} \mathrm{In}_{0.52}$ As epilayers increases with $\mathrm{T}_{\mathrm{g}}$. This could be attributed to an increase in Al composition with the increase in $\mathrm{Tg}$, since the XRD data show a decrease in In concentration, from $51.7 \%$ (at $470{ }^{\circ} \mathrm{C}$ ) to $50.4 \%\left(550^{\circ} \mathrm{C}\right.$ ), in the AlInAs alloy [see supplementary data, S4a (Ref. 45)].

The reduction in In concentration can be related to a temperature-dependent desorption of In atoms from the epilayer surface. The desorption of In atoms from AlInAs surface at a $\mathrm{T}_{\mathrm{g}}$ of $\sim 530^{\circ} \mathrm{C}$ has been previously reported. ${ }^{13,25}$ Another mechanism associated with material growth at high $\mathrm{T}_{\mathrm{g}}$, reported by Welch et al. ${ }^{26}$ is the desorption of As atoms from the AlInAs surface, which results in the formation of As vacancies. However, the overall effect of As vacancies on the lattice mismatch would be very small and could not be considered as the main reason for the observed lattice mismatch for the samples grown at high $\mathrm{T}_{\mathrm{g}}{ }^{27}$ Therefore, we consider that the dominant mechanism behind this lattice mismatch increase with $T_{g}$ is In desorption. In Fig. 2(a), the RMS roughness of layers shows an increase with the increase in $\mathrm{T}_{\mathrm{g}}$ (range $490-550^{\circ} \mathrm{C}$ ). However, in the range of $490-510^{\circ} \mathrm{C}$, the RMS roughness is almost insensitive to the $\mathrm{T}_{\mathrm{g}}$. Moreover, at $\mathrm{T}_{\mathrm{g}}$ in the range of $470-490^{\circ} \mathrm{C}$, the RMS roughness decreases with increasing $T_{g}$. Thus, in the $\mathrm{T}_{\mathrm{g}}$ range of $490-510^{\circ} \mathrm{C}$, we found the smallest RMS, which corresponds to a low lattice mismatch observed previously. Based on Fig. 2(a), we can deduce that the AlInAs epilayers have good crystalline quality and low strain. Besides, a low surface roughness can be achieved when growing AlInAs epilayers in the $\mathrm{T}_{\mathrm{g}}$ range of $490-510^{\circ} \mathrm{C}$. In such a range $\left(490-510^{\circ} \mathrm{C}\right)$, the lattice mismatch and the RMS values varied from 354 to $382 \mathrm{ppm}$ and from 0.2 to $0.26 \mathrm{~nm}$, respectively.

Figure 2(b) shows the lattice mismatch and RMS roughness variations as a function of $\mathrm{AsH}_{3}$ pressure at fixed $\mathrm{T}_{\mathrm{g}}$. We can see that the lattice mismatch and RMS as a function of $\mathrm{AsH}_{3}$ pressure show three distinct behaviors, which can be divided into three regions, i.e., between 3 and 10 Torr (region I), between 10 and 20 Torr (region II), and between 30 and 40 Torr (region III).

In region I, both the lattice mismatch and the RMS values decreased with increasing $\mathrm{AsH}_{3}$ pressure. It is plausible to consider that under these growth conditions, increasing the $\mathrm{AsH}_{3}$ pressure prevents the In desorption; hence, In-rich epilayers with improved crystalline and morphological properties were obtained. A similar trend has been reported in the literature. $^{26-28}$

In region II, lattice mismatch and RMS values were not affected by the $\mathrm{AsH}_{3}$ pressure changes, as they just varied from 252 to $264 \mathrm{ppm}$ and from 0.2 to $0.21 \mathrm{~nm}$, respectively. This suggested that in this region an increase in $\mathrm{AsH}_{3}$ pressure will not lead to the formation of localized strain at heterointerfaces. ${ }^{27,28}$
In region III, the lattice mismatch and RMS values show an abrupt increase with increasing $\mathrm{AsH}_{3}$ pressure. The epilayers in this region are Al-rich [see supplementary data, S4b (Ref. 45)]. The increase of lattice mismatch and RMS roughness with $\mathrm{AsH}_{3}$ pressure can be attributed to the $\mathrm{AsH}_{3}$ overpressure, which can decrease the surface mobility of $\mathrm{Al}$ and In cations, causing their clustering into In- and Al-rich regions. ${ }^{28}$ Welch et al. ${ }^{26}$ and Yoon ${ }^{28,29}$ studied the epitaxial growth of $\mathrm{Al}_{0.48} \mathrm{In}_{0.52} \mathrm{As}$ layers on InP substrates under $\mathrm{AsH}_{3}$ overpressure conditions and they observed the presence of minimum dips in the crystalline dependence on $\mathrm{AsH}_{3}$ pressure. However, no minimum dips were observed in our study. Nevertheless, our study reveals that by applying an $\mathrm{AsH}_{3}$ pressure in the range of 10-20 Torr during the growth, $\mathrm{Al}_{0.48} \mathrm{In}_{0.52}$ As epilayers with low strain and low RMS roughness can be obtained. It is worth to note that, from the guide-to-the-eye of Fig. 2(b), another sample at a 7 Torr $\mathrm{AsH}_{3}$ pressure would be expected to lead to a minimum lattice mismatch, but we did not dedicate the effort of growing an additional sample under such condition in the present study.

\section{Crystalline properties}

Based on the Al source calibration curve and the study of the growth temperature and $\mathrm{AsH}_{3}$ pressure effects, the following growth conditions were applied to calibrate the TMIn pressure and lattice mismatch: Al effusion cell temperature $=1050{ }^{\circ} \mathrm{C}, \mathrm{T}_{\mathrm{g}}=500^{\circ} \mathrm{C}$ and $\mathrm{AsH}_{3}$ pressure $=10$ Torr.

Figure 3(a) shows the lattice mismatch calculated as a function of TMIn pressure. As it can be seen, the lattice mismatch varies linearly with the TMIn pressure in the range of $0.53-0.56$ Torr. It also seems that there might be a bowing trend between lattice mismatch and TMIn pressure [Fig. 3(a)]. Nevertheless, a minimum lattice mismatch has been accurately predicted using a linear variation [see Fig. 3(b)]. Furthermore, within the investigated TMIn pressure range, the lattice mismatch changed from negative (tensile strain) to positive (compressive strain). This allows a direct adjustment of the In fraction in the alloy composition and, therefore, establishes a better control over the whole process for lattice mismatch calibration.

Figure 3(b) illustrates the measured HR-XRD rocking curve of (004) reflection from an AlInAs layer grown on InP substrates. The HR-XRD pattern shows the presence of a sharp peak and a shoulder that we assigned, respectively, to InP substrate and $\mathrm{Al}_{0.48} \mathrm{In}_{0.52} \mathrm{As}$ layer. This indicates the formation of a monocrystalline epilayer. The layer composition, calculated from the HR-XRD patterns, was $\sim 52 \%$ In and $\sim 48 \% \mathrm{Al}$ [see simulation in supplementary data, S3 (Ref. 45)] with a corresponding lattice mismatch as low as $134 \mathrm{ppm}$. This seems to be a good result of lattice mismatch compared to the literature results reported for both solid and gas source growth techniques. ${ }^{13,27,30}$ Besides, a very good vertical composition uniformity of samples was confirmed after performing XRD mapping on a full 2-in. wafer [see supplementary data, S7 (Ref. 45)]. The large number of Pendellösung fringes observed attests the growth of high crystalline quality epitaxial layers ${ }^{31}$ with a good 

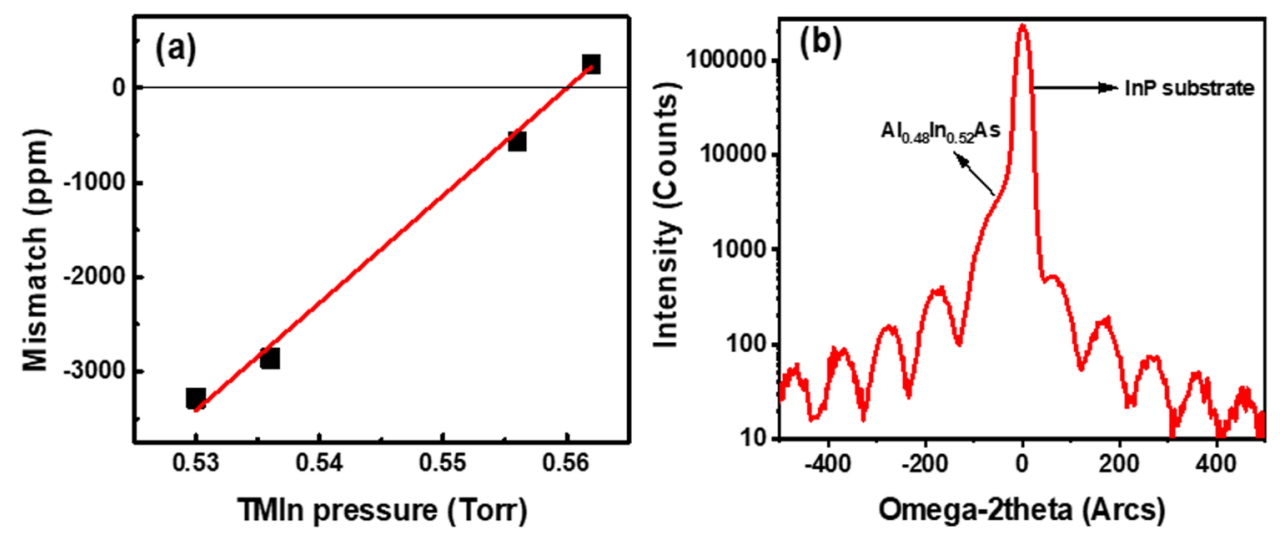

FIG. 3. (a) Lattice mismatch as a function of TMIn pressure and (b) HR-XRD rocking curve of (004) reflection of AlInAs/InP structure.

heteroepitaxial interface. The film thickness determined from these fringes was $\sim 200 \mathrm{~nm}$, which was in good agreement with the thickness measured by a profilometer and SEM (data not shown here). However, no Pendellösung fringes were observed for the epilayers grown by CBE with similar growth conditions and in the same chamber [see supplementary data, S2b (Ref. 45)]. Therefore, we may suggest that by using the hybrid epitaxy technique, high crystalline quality layers with low strain and good interface can be obtained. It is relevant to mention that the high crystalline quality of layer determined by HR-XRD is consistent with the RHEED pattern obtained during the growth [see supplementary data, S1a (Ref. 45)]. The observed streaky patterns were an indication of a good structure as well as a high crystalline quality layer, a layer by layer growth mode, ${ }^{14}$ and an atomically flat surface. $^{32}$

\section{Morphological properties}

Figures 4(a) and 4(b) show, respectively, the Nomarski micrograph and a $2 \times 2 \mu \mathrm{m}^{2}$ scanned area AFM image of the AlInAs layer surface. At the end of the growth process, the samples showed mirrorlike surfaces and, as shown in Fig. 4(a), such surfaces were featureless, homogeneous, and defect-free. In contrast, similar layers grown by CBE exhibited blurry surfaces with plenty of visible defects [see supplementary data, S2a (Ref. 45)]. Notice that the surface morphology of defect-free layers was identical to that of a bare epi-ready surface. The AFM characterization [see Fig. 4(b)] illustrates a very smooth surface with an RMS roughness of $0.2 \mathrm{~nm}$. This is consistent with the layer's crystalline quality presented in Fig. 3(b). For the investigated range of temperature and $\mathrm{AsH}_{3}$ pressure, no significant variation of the surface morphology was observed in Nomarski and AFM data.

\section{Optical properties and background doping}

To determine the optical properties of the as-grown layers, we performed LTPL at $20 \mathrm{~K}$. The LTPL spectra were collected from $200 \mathrm{~nm}$ thick and $4 \mu \mathrm{m}$ thick AlInAs layers as shown in Figs. 5(a) and 5(b), respectively.

The LTPL spectrum collected from the $200 \mathrm{~nm}$ thick AlInAs epilayer showed the presence of two sharp peaks at 1.49 and $1.508 \mathrm{eV}$, separated by an energy of $18 \mathrm{meV}$. The PL peak at $1.508 \mathrm{eV}$ corresponds to the AlInAs band edge emission and the PL peak at $1.49 \mathrm{eV}$ can be assigned to the transitions between an acceptor level and the conduction
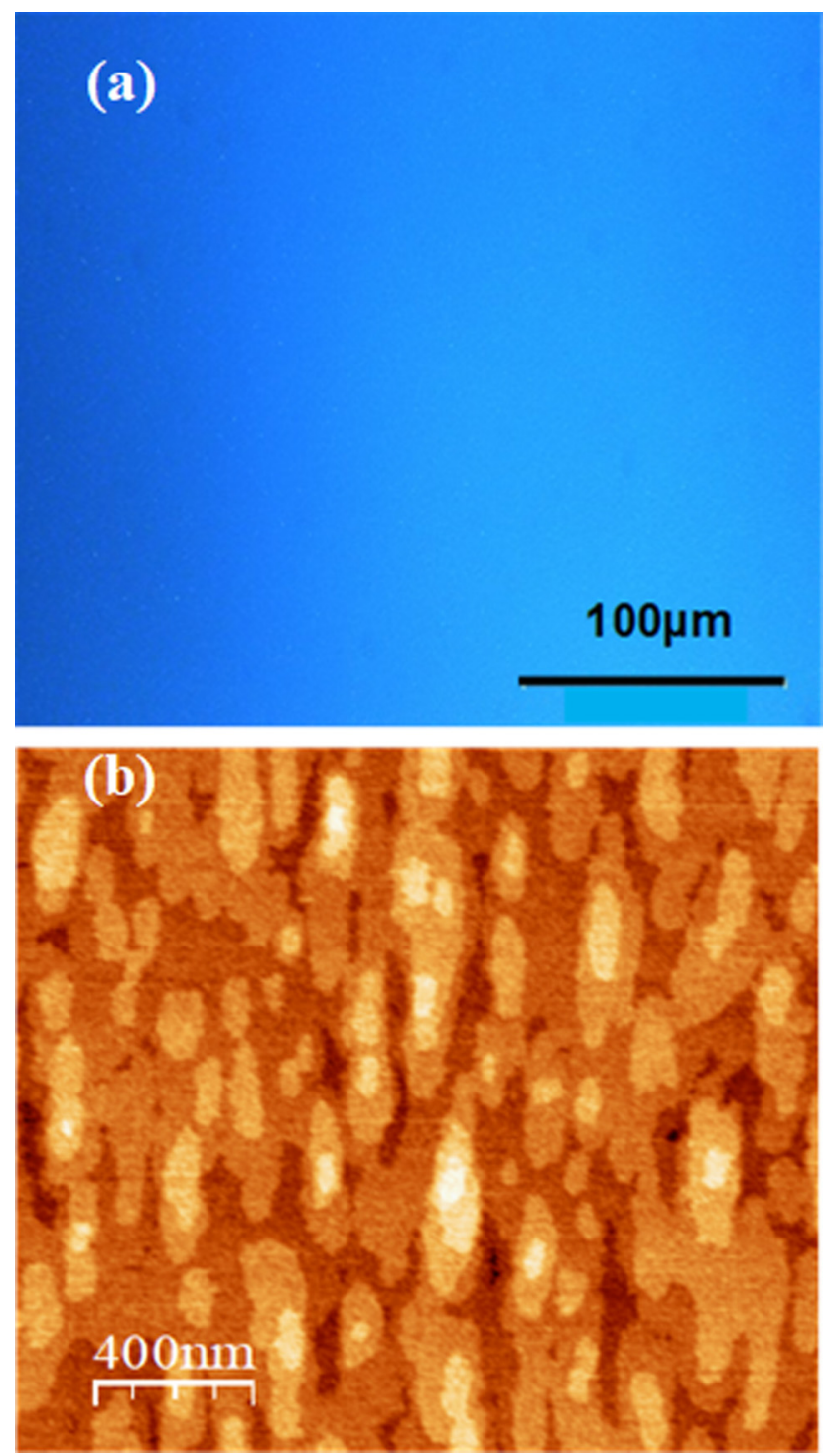

FIG. 4. (a) Nomarski micrograph and (b) $2 \times 2 \mu \mathrm{m}^{2}$ (1.63 nm Z-scale) scanned area AFM image of an AlInAs layer grown on $\operatorname{InP}(001)$ substrates at $\mathrm{T}_{\mathrm{g}}=500^{\circ} \mathrm{C}$. 

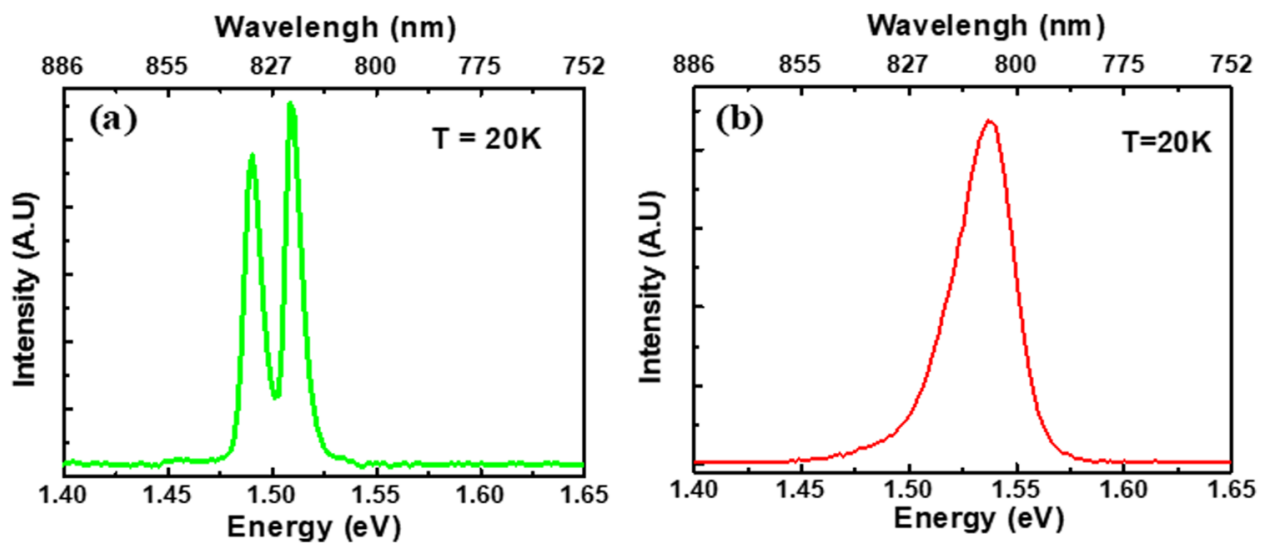

FIG. 5. LTPL spectra collected from AlInAs layers with a thickness of (a) $200 \mathrm{~nm}$ and (b) $4 \mu \mathrm{m}$.

band, originated from the unintentional doping of the layers by residual $\mathrm{C}$ ( $\mathrm{p}$-type doping) found in the chamber. Ribeiro et $a l .{ }^{33}$ reported the presence of a PL peak associated with a carbon-doped AlInAs, at $15 \mathrm{meV}$ below that of undoped AlInAs layer, which seems similar to our observation. The alloy composition extracted from Fig. 5(a) indicates a composition of $\sim 52 \%$ In and $48 \% \mathrm{Al}$ which is consistent with the values obtained from HR-XRD pattern in Fig. 3(b). The FWHM of the band edge emission peak is $8 \mathrm{meV}$, which is, to the best of our knowledge, one of the lowest values reported in the literature for this material even at temperatures lower than $20 \mathrm{~K} .{ }^{27,34,35}$ The layer optical quality is in good agreement with the crystalline quality displayed in Fig. 3(b). The narrow character of the PL peak indicates that clustering, which is mainly responsible for the broadening of the PL peak, is negligible. ${ }^{35}$ Moreover, such an intense band edge emission from the thin epilayer demonstrates a high optical quality and more likely the absence of deep-level carrier traps in the bandgap of the as-grown layers.

In Fig. 5(b), the LTPL spectrum collected from the $4 \mu \mathrm{m}$ thick AlInAs layer shows a single PL peak at $1.536 \mathrm{eV}$, which can be attributed to the band edge emission. The alloy concentration was determined to be $51 \%$ In and $49 \% \mathrm{Al}$, which is $1 \% \mathrm{Al}$ richer than the lattice-matched layers. The FWHM of this PL peak is $31 \mathrm{meV}$, approximately four times larger than the one found for the $200 \mathrm{~nm}$ thick AlInAs epilayer. This relatively large variance is consistent with the lattice mismatch difference between the two epilayers. A variation of the band edge PL peak position in the range of $1.5-1.536 \mathrm{eV}$ was observed for the grown lattice-matched epilayers. These values are similar to those reported by Aina et $a{ }^{31}$ Therefore, the linewidth and the intensity of the PL peaks reported here demonstrate a high optical quality of the as-grown layers. It is important to mention that no PL signal was observed from most of the samples grown at other temperatures than $500{ }^{\circ} \mathrm{C}$ and from the epilayers grown by standard CBE.

A free carrier density of $\sim 3 \times 10^{15} \mathrm{~cm}^{-3}$ was determined for the AlInAs epilayers grown by hybrid epitaxy, at $\mathrm{T}_{\mathrm{g}}=500{ }^{\circ} \mathrm{C}$ and $\mathrm{AsH}_{3}$ pressure of 10 Torr. Compared to the $\mathrm{CBE}$ in our facility, which results in a background doping as high as $10^{18} \mathrm{~cm}^{-3}$, the hybrid epitaxy offered
3 orders of magnitude lower background doping. Furthermore, Udhayasankar et $a l^{21}$ reported a background doping of $\mathrm{p}=2 \times 10^{18} \mathrm{~cm}^{-3}$ for AlInAs layers (thickness of $1 \mu \mathrm{m})$ grown by CBE. Hence, hybrid epitaxy seems to be suitable to grow high-quality epilayers for optoelectronic devices where the low background doping is of high importance for designing enhanced devices.

Given that optoelectronic devices require AlInAs/GaInAs heterostructures, the same $T_{g}$ would be desirable for the growth of these alloys in order to simplify the epitaxial growth process of the device. In addition, based on the growth parameters determined previously in the case of AlInAs, and those reported in the literature, ${ }^{36}$ we selected $\mathrm{T}_{\mathrm{g}}=500{ }^{\circ} \mathrm{C}$ to grow GaInAs epilayers by hybrid epitaxy.

\section{Growth of $\mathrm{Ga}_{0.47} \mathrm{In}_{0.53}$ As layers \\ 1. Crystalline properties}

The lattice mismatch calibration was performed by varying the TEGa pressure, while all the other growth parameters were kept constant, namely, In effusion cell temperature $=866^{\circ} \mathrm{C}$, $\mathrm{T}_{\mathrm{g}}=500^{\circ} \mathrm{C}$, and the growth rate $\sim 1.25 \mu \mathrm{m} / \mathrm{h}$. Figure $6(\mathrm{a})$ shows the lattice mismatch calculated as a function of TEGa pressure. We can notice that the lattice mismatch decreases linearly with the increase of the TEGa pressure that indicates a well-controlled process. Compared to the standard CBE [supplementary data, S7a (Ref. 45)], in hybrid epitaxy the variation of the TEGa pressure shows an almost 3 orders of magnitude lower effect on the lattice mismatch.

Based on the calibration curve [Fig. 6(a)], for hybrid epitaxy growth, a TEGa pressure of 1.12 Torr seemed suitable for the growth of lattice-matched GaInAs/InP. Also, the RHEED showed streaky patterns, which become more intense during the growth, indicating a 2D growth mode, a good crystalline quality, well-ordered and flat surface. ${ }^{14,37}$

Figure 6(b) shows the HR-XRD rocking curve of (004) reflection from a GaInAs epilayer. The XRD pattern with numerous Pendellösung fringes reflects, similar to the case of AlInAs, a good crystalline quality layer with a good heterointerface. $^{38}$ The FWHM of the layer was 18.5 arcs, which is close to 16.5 arcs corresponding to the same alloy grown by standard $\mathrm{CBE}$ at $\mathrm{T}_{\mathrm{g}}=500{ }^{\circ} \mathrm{C}$ in our facility [see 

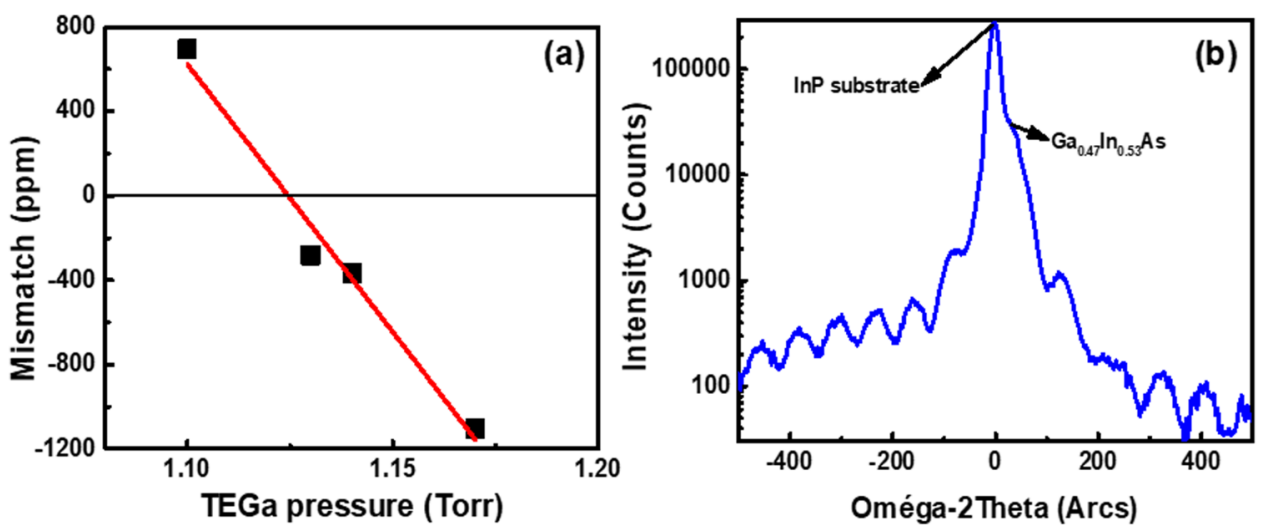

FIG. 6. (a) Lattice mismatch as a function of TEGa pressure and (b) HR-XRD rocking curve of (004) reflection of lattice-matched GaInAs/InP structure.

supplementary data, S7b (Ref. 45)]. These values seem to be smaller compared to the values reported in the literature for the epilayers grown by standard CBE and MOCVD techniques, ${ }^{18,38,39}$ confirming the high crystalline quality. The layer thickness was $\sim 350 \mathrm{~nm}$ from the Pendellösung fringes, which agrees with the value obtained by a profilometer and SEM (not shown here). Moreover, the layer composition and lattice mismatch were calculated from HR-XRD measurements. The GaInAs epilayer composition was determined to be $53 \%$ In and $47 \%$ Ga with a tensile lattice strain of $-96 \mathrm{ppm}$, comparable to $-85 \mathrm{ppm}$ obtained for epilayer grown by CBE.

The GaInAs/InP lattice mismatch homogeneity was also investigated by performing HR-XRD on a full 2-in. wafer at different positions [see the measurement points in supplementary data, S7c (Ref. 45)]. The measurements revealed a standard deviation of $\pm 263 \mathrm{ppm}(0.026 \%)$, which is within our targeted range $[-500 ;+500] \mathrm{ppm}$. This standard deviation attests the uniformity of the composition along the wafer and seems to present a lower standard deviation than what was reported previously regarding In-soldered mounting wafers. ${ }^{38} \mathrm{We}$ consider that the In-soldered mounting substrate has a contribution in the obtained result since it allows a more steady growth temperature of the sample; thus, a more uniform growth could be achieved. ${ }^{38}$

\section{Morphological properties}

Figure 7 illustrates the DIC Nomarski and AFM surface images obtained from a GaInAs epilayer grown on InP (001) substrates. As it can be seen in Fig. 7(a), employing the hybrid epitaxy results in the growth of epilayers with featureless, homogeneous, and defect-free surfaces. The $2 \times 2 \mu \mathrm{m}^{2}$ scanned area AFM image, shown in Fig. 7(b), reveals a smooth surface with an RMS of $1 \mathrm{~nm}$. The epilayer grown at the same $\mathrm{T}_{\mathrm{g}}$ by the standard CBE exhibited a slightly lower RMS value of $\sim 0.82 \mathrm{~nm}$ determined from a $2 \times 2 \mu \mathrm{m}^{2}$ scanned area AFM image [see supplementary data, S6b (Ref. 45)]. The slight difference in the morphological features observed between the layers grown by hybrid epitaxy and standard CBE could be attributed to the nature of precursors, i.e., gas source (molecules) versus solid (atoms). In hybrid epitaxy, once we inject both atoms and molecules, concurrently, their interaction leads to a reduction of molecules mobility on the surface, since molecules kinetically move faster than atoms. This leads to a different growth dynamic compared to the standard CBE

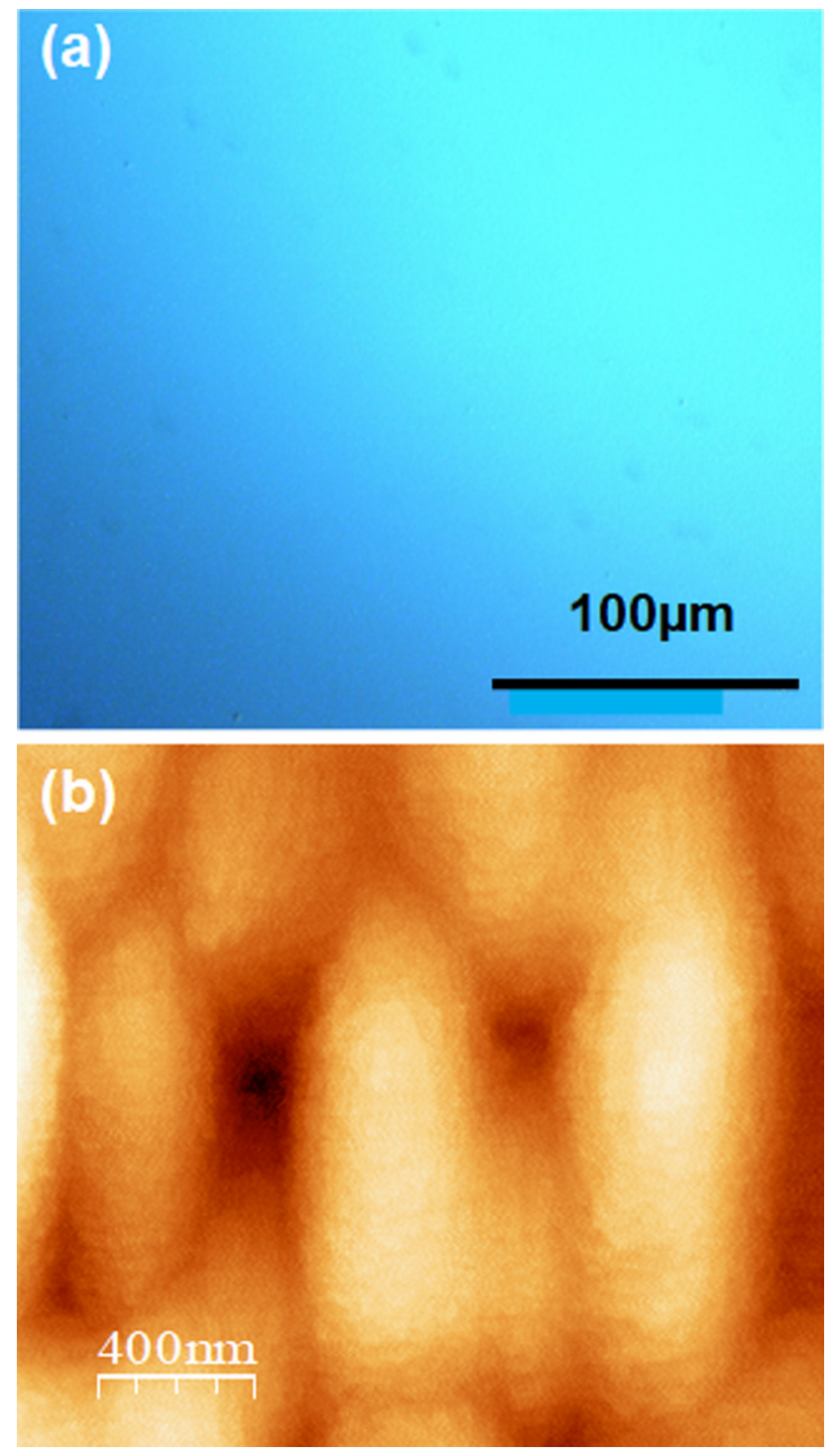

FIG. 7. (a) Nomarski micrograph and (b) $2 \times 2 \mu \mathrm{m}^{2}$ (7.33 nm Z-scale) scanned AFM image of GaInAs epilayer grown on InP (001). 


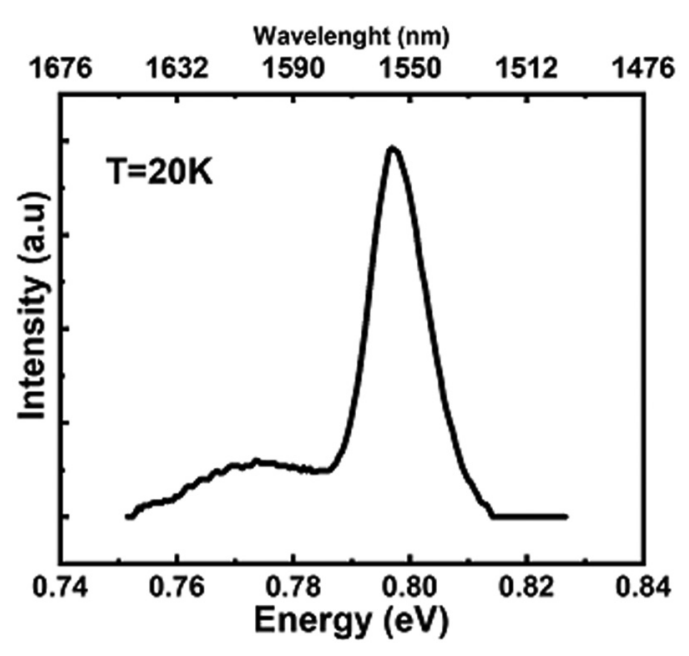

FIG. 8. LTPL spectrum collected at $20 \mathrm{~K}$ from a $2.5 \mu \mathrm{m}$ thick GaInAs layer.

and, eventually, results in the appearance of dissimilar morphology features as observed from AFM images of the GaInAs layers grown by both epitaxy techniques.

Based on the obtained RMS roughness for GaInAs layers grown by these techniques at $\mathrm{T}_{\mathrm{g}}=500^{\circ} \mathrm{C}$, we may consider that a higher growth temperature could improve the morphology of hybrid grown GaInAs layers.

\section{Optical properties and background doping}

Background doping was determined by Hall effect measurements at $300 \mathrm{~K}$, on a $2.5 \mu \mathrm{m}$ thick GaInAs layer, grown at $\mathrm{T}_{\mathrm{g}}=500^{\circ} \mathrm{C}$. The layer background doping density was found to be $1 \times 10^{15} \mathrm{~cm}^{-3}$ with electrons as majority carriers. This is 1 order of magnitude lower compared to the background doping of the GaInAs epilayers grown by the standard CBE in our facility, at the same $\mathrm{T}_{\mathrm{g}}$ and $\mathrm{AsH}_{3}$ pressure [supplementary data, S8 (Ref. 45)]. This result suggests that the hybrid epitaxy technique can satisfy the requirements of growing GaInAs epilayers with low background doping and high crystalline quality for fabrication of high performance APD devices. The layers residual doping reported here is lower, compared to the value of the same alloy grown by CBE for APD applications. ${ }^{40}$
Figure 8 shows the LTPL spectrum collected at $20 \mathrm{~K}$ from a $2.5 \mu \mathrm{m}$ thick GaInAs layer grown by the hybrid epitaxy technique grown at $\mathrm{T}_{\mathrm{g}}=500{ }^{\circ} \mathrm{C}$. We can observe two PL peaks at energies of 0.773 and $0.796 \mathrm{eV}$. The narrow and intense peak at $0.796 \mathrm{eV}$ corresponds to GaInAs band-toband emission, and it is characterized by an FWHM of $9.7 \mathrm{meV}$. Wang et al. reported a comparable FWHM value for GaInAs bulk epilayer grown by MBE, measured at $10 \mathrm{~K}^{41}$ In addition, LTPL measurements were performed at $32 \mathrm{~K}$ on GaInAs layers grown by both hybrid epitaxy and standard CBE [see supplementary data, S8 (Ref. 45)] at $\mathrm{T}_{\mathrm{g}}=500^{\circ} \mathrm{C}$, for comparison. GaInAs epilayer grown by standard CBE exhibited a band-to-band emission with an FWHM of $18 \mathrm{meV}$, which is $\sim 4 \mathrm{meV}$ higher than the one obtained for the epilayers grown by hybrid epitaxy. This suggests that the hybrid epitaxy technique can result in the growth of GaInAs layers with a higher purity and a better optical quality compared to standard CBE technique.

The small broad peak observed at $0.773 \mathrm{eV}$ could be attributed to a variation in the alloy composition, also known as spinodal decomposition. This phenomenon has been observed for GaInAs in MBE (Ref. 42) and MOCVD, ${ }^{18}$ where they increase the growth temperature, respectively, from 470 to $530{ }^{\circ} \mathrm{C}$ and 620 to $707^{\circ} \mathrm{C}$. It can restrict the electrical performance of high-speed devices such as APDs. However, the LTPL spectrum collected from the layers grown by standard CBE in our facility did not show the presence of such a peak. The sensitivity of GaInAs composition to the growth temperature variations during the growth process has been previously reported. ${ }^{4}$ It has been argued that growth of uniform composition layers requires temperature stability. Based on our results and the reported studies, we may assume that growing high-quality epilayers by hybrid epitaxy should be performed at higher $T_{g}$. Subsequently, we have investigated the effect of growth temperature on the composition and roughness.

\section{Effect of growth temperature}

To study the effect of growth temperature on GaInAs layer composition and roughness, the growth temperature was varied in the range of $470-540{ }^{\circ} \mathrm{C}$ while all the other parameters were kept constant, i.e., In solid source
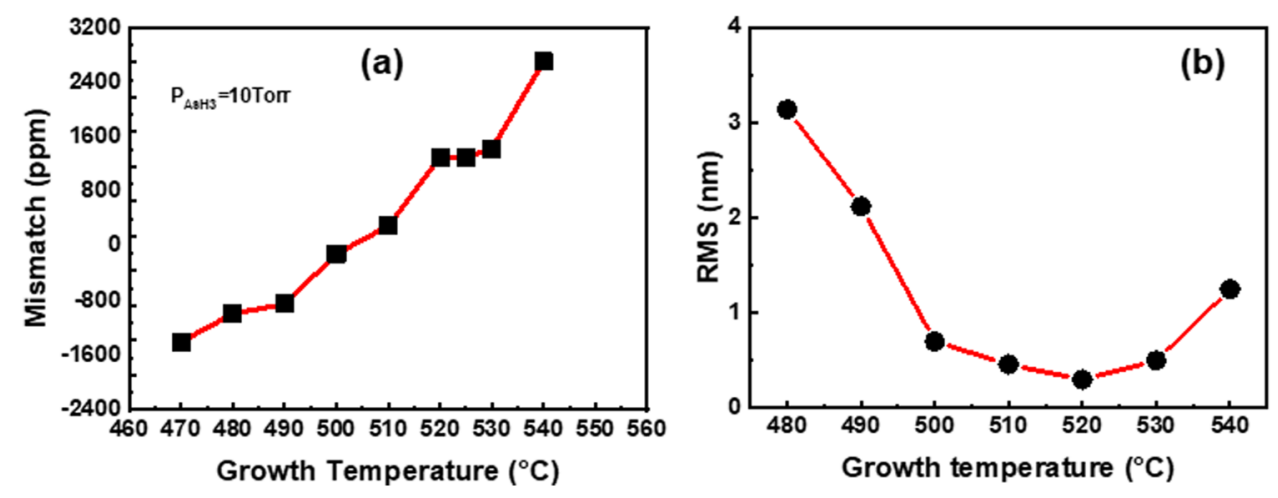

FIG. 9. (a) GaInAs lattice mismatch and (b) RMS roughness measured as a function of growth temperature. 
temperature $=866^{\circ} \mathrm{C}$, TEGa pressure $=1.224$ Torr, and $\mathrm{AsH}_{3}$ pressure $=10$ Torr.

The growth temperature effect on GaInAs lattice mismatch is shown in Fig. 9(a). As it can be seen, the lattice mismatch increases with the increase of growth temperature. However, in the range of $520-530^{\circ} \mathrm{C}$, the lattice mismatch seems to remain nearly constant with a maximum variation of $\sim 128 \mathrm{ppm}$. This suggests that the composition is almost insensitive to the growth temperature within $520-530^{\circ} \mathrm{C}$ range.

In addition, increasing the growth temperature above $530^{\circ} \mathrm{C}$ leads to the growth of In-rich alloys [see supplementary data, S9 (Ref. 45)], with an increase of the compressive strain. The In enrichment could be explained by two mechanisms: (i) the In-As weak bond strength, compared to Ga-As bond and the $\mathrm{AsH}_{3}$ overpressure, allows the In enrichment of the alloys at low temperature. ${ }^{4}$ In addition, Ga precursor would be desorbed at low temperature; therefore, it reduces the rate at which Ga species are arriving at the substrate surface ${ }^{43}$ and (ii) at high temperatures, In species tend to saturate the surface, therefore inhibit the Ga precursor decomposition. This phenomenon has been reported in the literature as In segregation. ${ }^{44}$ Singh et al. reported a similar effect for GaInAs epilayers grown by CBE technique, i.e., increasing the growth temperature $\left(490-540{ }^{\circ} \mathrm{C}\right)$ resulted in an increase of In incorporation. ${ }^{4}$

Figure 9(b) presents the measured roughness RMS of epilayers as a function of $T_{g}$. An increase in the $T_{g}$ results in a decrease of epilayers roughness, with a minimum RMS of $0.34 \mathrm{~nm}$ for the epilayer grown at $\mathrm{T}_{\mathrm{g}}=520^{\circ} \mathrm{C}$. Hence, a relatively smooth GaInAs epilayer surface can be grown at $T_{g}$ of $520^{\circ} \mathrm{C}$ compared to the GaInAs layers grown at $\mathrm{T}_{\mathrm{g}}=500^{\circ} \mathrm{C}$. The lower RMS values obtained for the layers grown at $\mathrm{T}_{\mathrm{g}}=520^{\circ} \mathrm{C}$ compared to the ones grown at lower $\mathrm{T}_{\mathrm{g}}$ $\left(500^{\circ} \mathrm{C}\right)$ can be explained by an increase of adatoms migration on the layer surface. A similar effect has been reported by another research group. ${ }^{14} \mathrm{~A}$ slight increase of the RMS is observed for the layers grown at $\mathrm{T}_{\mathrm{g}}=540^{\circ} \mathrm{C}$. Since we did not observe In desorption at this growth temperature, this increment of the RMS could be due to the As desorption, which results in the degradation of the surface. The high surface roughness observed at low temperatures could be attributed to the lateral alloy decomposition (also known as spinodal decomposition), which can reduce carriers mobility. ${ }^{42}$ This seems to be in good agreement with the hypothesis that we made in Secs. III C 2 and III C 3, as well as with the composition variation observed by LTPL (see Fig. 8), i.e., the presence of the broad peak at $0.773 \mathrm{eV}$ in the case of epilayers grown at $\mathrm{T}_{\mathrm{g}}=500^{\circ} \mathrm{C}$.

Figure 10 shows the LTPL spectra collected at $20 \mathrm{~K}$ from the epilayers grown with various growth temperatures. Note that these spectra were recorded with the same parameters and the PL peaks have been shifted at the same energy to be easily compared. The LTPL spectra show that an increase in growth temperature results in a decrease of the broad peak (positioned at $0.76 \mathrm{eV}$ ) intensity, which was initially attributed to the spinodal decomposition. ${ }^{18}$ This advocated the idea that higher growth temperature offers a better layer

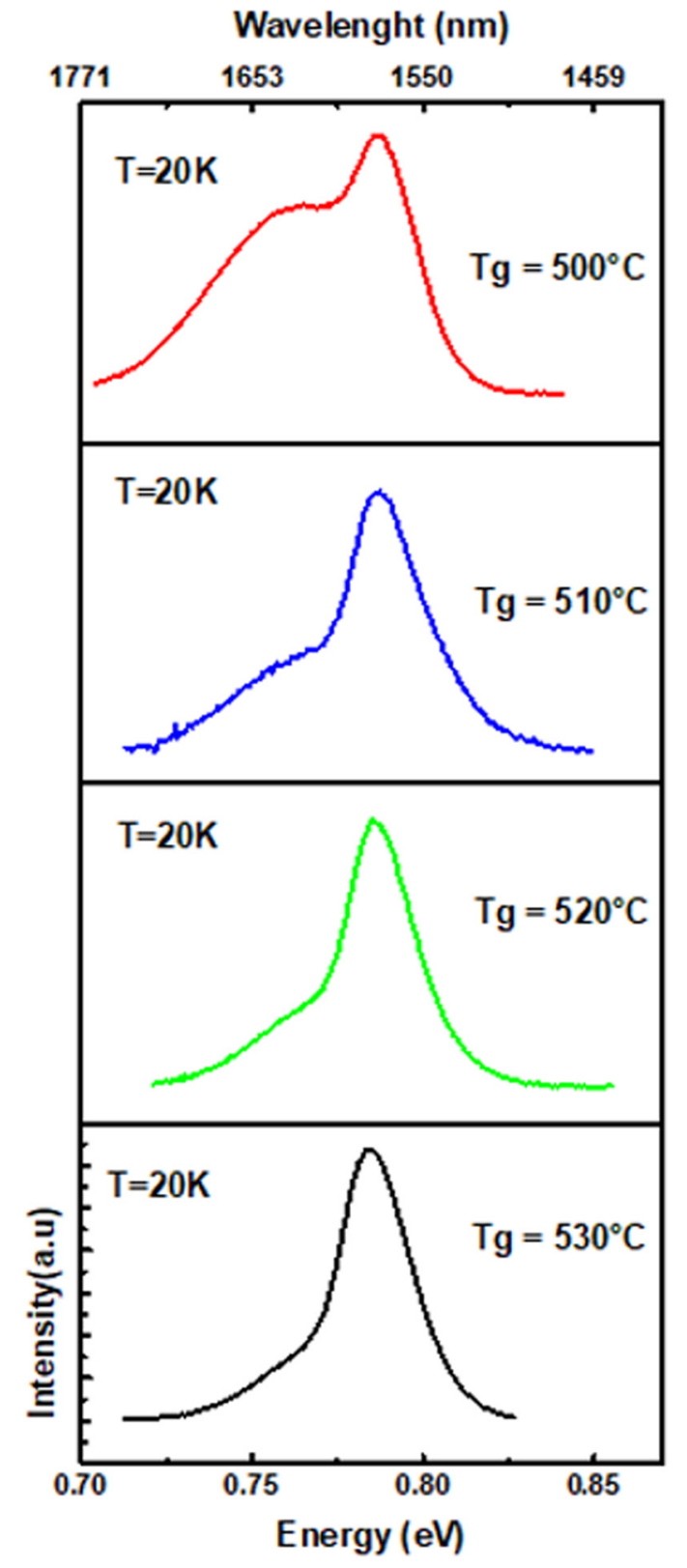

FIG. 10. LTPL spectra collected at $20 \mathrm{~K}$ on $350 \mathrm{~nm}$ thick hybrid GaInAs epilayers grown at different growth temperatures.

uniformity. Based on the results, in order to obtain highquality GaInAs epilayer with a better uniform composition, the growth should be performed in the temperature range of $520-530{ }^{\circ} \mathrm{C}$. Even though the XRD data at $\mathrm{T}_{\mathrm{g}}=500^{\circ} \mathrm{C}$ showed that CBE grown GaInAs epilayers had slightly better characteristics compared to the hybrid grown epilayers, employing the same growth conditions, the PL data show the superiority of hybrid technique over CBE, since the FWHM of PL peaks was largely dissimilar.

\section{CONCLUSIONS}

In this paper, the growth of high-quality AlInAs and GaInAs epilayers on InP substrates by hybrid epitaxy technique has been demonstrated. The growth temperature $\left(\mathrm{T}_{\mathrm{g}}\right)$ and the arsine $\left(\mathrm{AsH}_{3}\right)$ pressure effects on the structural, 
morphological, and optical properties of AlInAs and GaInAs epilayers have been studied. Through this study, we determined the optimum range for growing lattice-matched layers with a high crystalline quality. It was observed that an increase in the $\mathrm{T}_{\mathrm{g}}$ leads to the growth of Al-rich layers, in the case of AlInAs, because of In desorption. However, in the case of GaInAs, the $T_{g}$ increment resulted in the growth of In-rich layers, since no In desorption was observed in the studied range.

Remarkably smooth surfaces with lattice mismatch as low as 134 and $-96 \mathrm{ppm}$ have been obtained for AlInAs and GaInAs epilayers, respectively. The HR-XRD patterns displayed a large number of Pendellösung fringes, confirming the good crystalline quality of AlInAs and GaInAs epilayers. In the case of GaInAs layers, we found an FWHM of 18.5 arcs and a lattice mismatch uniformity with a standard deviation of $0.026 \%$ (on full 2-in. wafer). The LTPL measurements collected at $20 \mathrm{~K}$ confirmed that lattice-matched AlInAs and GaInAs epilayers were grown. AlInAs epilayer showed a PL peak around $1.51 \mathrm{eV}$ and with an FWHM value of $8 \mathrm{meV}$. On the other hand, GaInAs showed a PL peak of $0.796 \mathrm{eV}$ and an FWHM value of $9.7 \mathrm{meV}$. This demonstrates that hybrid epitaxy technique can be employed to grow AlInAs and GaInAs epilayers with a high crystalline and optical quality. In addition, this technique allows growing epilayers with low background doping, in the order of $10^{15} \mathrm{~cm}^{-3}$, which is essential for designing advanced devices such as avalanche photodiodes, HEMTs, and lasers.

\section{ACKNOWLEDGMENTS}

The authors would like to thank H. Pelletier, G. Bertrand, and P. O. Provost for the technical help, G. Gommé for scientific discussions, the Natural Sciences and Engineering Research Council of Canada (NSERC), and the Fonds de Recherche du Quebec-Nature et Technologies (FRQNT) for financial support.

${ }^{1}$ B. R. Bennett and J. A. Del Alamo, J. Appl. Phys. 73, 3195 (1993).

${ }^{2}$ C. Lenox, P. Yuan, H. Nie, O. Baklenov, C. Hansing, J. C. Campbell, A. L. Holmes, and B. G. Streetman, Appl. Phys. Lett. 73, 783 (1998).

${ }^{3}$ D. S. G. Ong, J. S. Ng, L. J. J. Tan, C. H. Tan, and J. P. R. David, 2007 International Conference on Indium Phosphide and Related Materials, Conference Proceedings, Matsue, Japan, 14-18, May 2007 (IEEE, 2007), pp. 296-298.

${ }^{4}$ N. K. Singh, J. S. Foord, P. J. Skevington, and G. J. Davies, J. Cryst. Growth 120, 33 (1992).

${ }^{5}$ W. Lee, J. Vac. Sci. Technol. B 4, 536 (1986).

${ }^{6}$ W. T. Tsang, A. H. Dayem, T. H. Chiu, J. E. Cunningham, E. F. Schubert, J. A. Ditzenberger, J. Shah, J. L. Zyskind, and N. Tabatabaie, Appl. Phys. Lett. 49, 170 (1986).

${ }^{7}$ C. W. D. C. Reynolds and K. K. Bajaj, Phys. Rev. B 29, 7038(R) (1984).

${ }^{8}$ F. Y. Juang, Y. Nashimoto, and P. K. Bhattacharya, J. Appl. Phys. 58, 1986 (1985).

${ }^{9}$ W. Hong, A. Chin, N. Debbar, J. Hinckley, P. K. Bhattacharya, and J. Singh, J. Vac. Sci. Technol. B 5, 800 (1987).

${ }^{10}$ W. P. Hong, P. K. Bhattacharya, and J. Singh, Appl. Phys. Lett. 50, 618 (1987).

${ }^{11}$ A. Sayari, N. Yahyaoui, M. Oueslati, H. Maaref, and K. Zellama, J. Raman Spectrosc. 40, 1023 (2009).
${ }^{12}$ V. S. Sundaram, L. M. Fraas, and C. C. Samuel, J. Elect. Mater. 20, 2 (1991).

${ }^{13}$ R. Bhat, M. A. Koza, K. Kash, S. J. Allen, W. P. Hong, S. A. Schwarz, G. K. Chang, and P. Lin, J. Cryst. Growth 108, 441 (1991).

${ }^{14}$ C. D. Yerino, B. Liang, D. L. Huffaker, P. J. Simmonds, and M. L. Lee, J. Vac. Sci. Technol. B 35, 010801 (2017).

${ }^{15}$ S. F. Yoon, Y. B. Miao, and K. Radhakrishnan, Thin Solid Films 279, 11 (1996).

${ }^{16}$ I. Demir and S. Elagoz, Superlattices Microstruct. 104, 140 (2017).

${ }^{17}$ D. A. Andrews and G. J. Davies, J. Appl. Phys. 67, 3187 (1990).

${ }^{18}$ S. J. Bass, S. J. Barnett, G. T. Brown, N. G. Chew, A. G. Cullis, A. D. Pitt, and M. S. Skolnick, J. Cryst. Growth 79, 378 (1986).

${ }^{19}$ J. L. Benchimol, F. Alexandre, Y. Gao, and F. Alaoui, J. Cryst. Growth 95, 150 (1989).

${ }^{20}$ S. S. S. F. Yoon, Y. B. Miao, and K. Radhakrishnan, Mater. Res. 2749 (1996).

${ }^{21}$ M. Udhayasankar, J. Kumar, and P. Ramasamy, J. Cryst. Growth 268, 389 (2004).

${ }^{22} \mathrm{M}$. Uchida and G. Araki, International Conference on Indium Phosphide and Related Materials, Conference Proceedings, Princeton, NJ, 8-11 May 2006 (IEEE, 2006), p. 396.

${ }^{23}$ A. Chandra, C. E. C. Wood, D. W. Woodard, and L. F. Eastman, Solid State Electron. 22, 645 (1979).

${ }^{24}$ See: www.leguideits.fr (n.d.)

${ }^{25}$ E. Tournié, Y. H. Zhang, N. J. Pulsford, and K. Ploog, J. Appl. Phys. 70, 7362 (1991).

${ }^{26}$ D. F. Welch, G. W. Wicks, L. F. Eastman, P. Parayanthal, and F. H. Pollak, Appl. Phys. Lett. 46, 169 (1985).

${ }^{27}$ S. F. Yoon, Y. B. Miao, K. Radhakrishnan, and S. Swaminathan, Mater. Sci. Eng. B Solid State Mater. Adv. Technol. 35, 109 (1995).

${ }^{28}$ S. F. Yoon, Superlattices Microstruct. 23, 535 (1998).

${ }^{29}$ S. F. Yoon, J. Cryst. Growth 178, 207 (1997).

${ }^{30}$ W.-Y. Choi, J. Vac. Sci. Technol. B 12, 1013 (1994).

${ }^{31}$ L. Aina, M. Mattingly, A. Fathimulla, E. A. Martin, L. Tom, and L. Stecker, J. Cryst. Growth 93, 911 (1988).

${ }^{32}$ J. E. Ayers, Heteroepitaxy of Semiconductors Theory, Growth, and Characterization (Taylor \& Francis, London, 2007).

${ }^{33}$ M. L. P. Ribeiro, B. Yavich, C. V. B. Tribuzy, and P. L. Souza, Braz. J. Phys. 32, 362 (2002).

${ }^{34}$ G. J. Davies et al., J. Vac. Sci. Technol. B 2, 219 (1984).

${ }^{35}$ S. M. Olsthoorn, F. A. J. M. Driessen, A. P. A. M. Eijkelenboom, and L. J. Giling, J. Appl. Phys. 73, 7798 (1993).

${ }^{36}$ J. F. Carlin, A. Rudra, and M. Ilegems, J. Cryst. Growth 164, 470 (1996).

${ }^{37}$ K. S. K. Minami, J. Jogo, Y. Morishita, and T. Ishibashi, Polym. Sci. Technol. 42, T1 (2005).

${ }^{38}$ F. Genova, G. Morello, G. Autore, and L. Gastaldi, J. Cryst. Growth 107, 1065 (1991).

${ }^{39}$ M. Udhayasankar, J. Kumar, and P. Ramasamy, J. Optoelectron. Adv. Mater. 5, 75 (2003).

${ }^{40}$ B. C. Johnson, IEEE J. Quant. Elect. 24, 496 (1988).

${ }^{41}$ Y. Wang et al., Nanoscale Res. Lett. 12, 229 (2017).

${ }^{42}$ A. C. M. Hjiri, A. Ben Jazia, H. Mejri, F. Hassen, H. Maaref, and F. Peiro, Microelectron. Eng. 51-52, 461 (2000).

${ }^{43}$ G. J. Davies, W. T. Tsang, and J. S. Foord, Chemical Beam Epitaxy and Related Techniques (Wiley, New York, 1997).

${ }^{44}$ Y. Iimura, K. Nagata, Y. Aoyagi, and S. Namba, J. Cryst. Growth 105, 230 (1990).

${ }^{45}$ See supplementary material at https://doi.org/10.1116/1.5088962 for S1: In-situ Reflection High-Energy Electron Diffraction (RHEED) of hybrid AlInAs epilayers. S2: Growth of AlInAs epilayers on InP (100) substrates by CBE using TriEthylAluminum (TEAl) precursor. S3: Leptos simulation of HR-XRD rocking curve for lattice matched AlInAs/InP grown by hybrid epitaxy. S4: Variation of In fraction in hybrid AlInAs epilayers as a function of growth parameter. S5: In-situ RHEED of GaInAs layers grown by CBE and hybrid epitaxy. S6: Surface morphology of GaInAs epilayers grown by CBE using TEGa and TMIn precursors. S7: Crystalline properties of GaInAs epilayers grown by CBE. S8: LTPL measurements of GaInAs epilayers grown by CBE technique. S9: Variation of In and Ga fractions in hybrid GaInAs epilayers as a function of $\mathrm{T}_{\mathrm{g}}$. 